\title{
6
}

\section{Relativism, Vagueness and What is Said}

\author{
Manuel García-Carpintero
}

In a series of recent papers, John MacFarlane (2003, 2005a, 2005b) has formulated a version of truth-relativism, and argued for its application in some cases - future contingents, knowledge attributions and epistemic modals among them. Mark Richard (2004) also defends a version of relativism, which he applies to vagueness-inducing features of the semantics of gradable adjectives; Richard thinks that it provides a model to properly articulate contextualist intuitions about knowledge attributions. On MacFarlane's characterization, and on Richard's as I will be interpreting it, truth-relativist claims posit a distinctive kind of context-dependence, to be distinguished from the more familiar one that has been closely studied since Kaplan's (1989) work in the 1970s. Radical truth-relativists posit the dependence of the evaluation of an assertion as true or otherwise on aspects of the context of the evaluation itself - in contrast with the context of the assertion.

The main motivation for truth-relativism is to make sense of alleged cases of "faultless disagreement". These are cases of "substantive disagreement" (Richard, op. cit., 219) between two thinkers, "in the sense that one asserts something that is inconsistent with what the other asserts" (ibid.: 218), while, nonetheless, neither of them is at fault, with respect to the fundamental norms to evaluate acts of assertion such as those they are engaged in, and in some unexpected way: it cannot just be that they are talking about different subject-matters, without realizing it, so that in fact there is no real inconsistency; or that both assertions are equally well justified, given the evidence available to the asserters, although at

\footnotetext{
Research for this paper is supported by the European Science Foundation EUROCORES program "The Origin of Man, Language and Languages" by the Spanish Government's grant MCYT BFF2002-10164 and research project HUM2004-05609-C02-01, by the DURSI, Generalitat de Catalunya, SGR01-0018, and by a Distinció de Recerca de la Generalitat, Investigadors Reconeguts 2002-2008. I am very grateful to José Díez, Max Kölbel, Dan López de Sa, Teresa Marques and Genoveva Martí for their suggested revisions on previous versions that led to improvements. The paper was presented at the Logos Relativizing Utterance Truth Conference and the Logos Seminar. I thank the audiences there for helpful criticism. I am also indebted to Michael Maudsley for his grammatical revision.
}

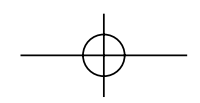


most one is true. ${ }^{1}$ Throughout the paper I will further characterize these alleged cases of substantive faultless disagreements, as understood by truth-relativists, and I will argue that they have not given us good reasons to think that there are any; we must do with this negative description for the moment.

My main goal in this paper is to argue against the truth-relativist proposals for gradable adjectives in Richard (2004). I intend my points to apply mutatis mutandis to knowledge attributions and epistemic modals, but I will not discuss them here, because they introduce complexities of their own which require independent treatment. An ancillary goal (which, notwithstanding its ancillary character, will take up a good portion of the paper) is to better understand what is at stake in these debates, a matter on which I do not find current literature sufficiently clear. In particular, following the lead of Evans' (1985) earlier critical examination of the issues, I will distinguish a moderate from the radical version of the view that I understand MacFarlane and Richard defend. Unlike the radical ones, moderate versions relativize contents in unusual ways, but they do not go on to relativize in addition the norms of speech acts with those contents, in particular the truth of assertions with those contents. As a result, I will argue, although they are semantically in well standing, and they are correct in some cases, including in particular the case of gradable adjectives that I will be discussing here, they cannot do justice to what it is advertised by way of accounting for alleged cases of faultless disagreement. Radical versions can, precisely because they do relativize not just contents but the norms of speech acts in addition; but it is unclear whether they are intelligible, precisely on account of that.

The paper is structured in two sections. In the first, I will provide an initial characterization of what is at stake in the truth-relativism debates, and I will also outline what I take to be the fundamental worries about radical truthrelativism. In the second I will present the evidence for a relativist treatment of gradable adjectives, examining the extent to which Richard's proposal appears to be relativist in the radical sense-while, for instance, the similarly sounding one by Egan, A., Hawthorne, J. and Weatherson, B. (2005) counts only as moderate. Then I will propose a more orthodox semantic way of dealing with the evidence for truth-relativism about gradable adjectives, a moderate relativist account.

\subsection{VARIETIES OF TRUTH-RELATIVISM}

For reasons I hope to make clear presently, in order to properly characterize what is at stake in these debates we should appeal to the vexed notions of saying and

1 Cf. MacFarlane (2007) for his own attempt at stating the phenomenon; the paper also attests to the relevance that the phenomenon has for him, even if he had previously avoided the notion. 


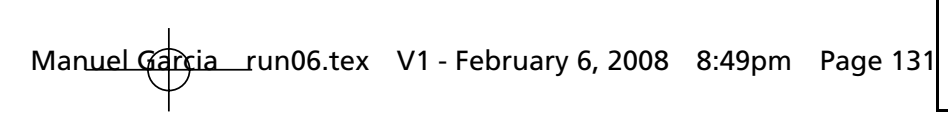

Relativism, Vagueness and What is Said

what is said; vexed because, as several writers have argued, our practices in making claims involving those notions, and the intuitions that go with them, evince a truly complex picture. ${ }^{2}$ This has been already pointed out in a paper I will be drawing on later: "Unless we give it some special technical meaning, the locution 'what is said' is very far from univocal" (Lewis 1980: 41). However, against what some of those writers suggest, there are theoretically significant notions that can be reconstructed out of those practices and intuitions, traditionally understood to be fundamental in semantic theorizing.

There are, in fact, two different theoretically significant notions of what is said, related to what I will distinguish as locutionary and illocutionary sayings: the main interpretative claim I will be defending here is that, in critically examining the relativism debates, we must distinguish truth as applying to illocutionary sayings, from its use in applying to locutionary sayings. Moderate truth-relativism has to do with whether or not truth for what is said in the locutionary sense is more or less relativized in unexpected ways, while keeping truth for what is said in the illocutionary sense absolute; radical truth-relativism has to do with whether or not truth as a feature of illocutions should in addition be relativized. There is a general point here, that in philosophical discussions of the concept of truth we should keep in clear sight, namely, the distinction between truth as predicated of speech acts such as assertions and truth as predicated of contents. An intuitive consideration is that we do not evaluate as true or false questions, promises or orders, even though they might have the same content as an assertion, say the same in the locutionary sense. I will not discuss further the general issue. What matters to us is that it is both the truth of locutions and illocutions, not just the latter, which is at stake in the relativism debate-and hence that issues exactly paralleling those we will be confronting arise regarding, say, compliance for promises and obedience for orders.

Grice appealed to the notion of what is said, in his struggle to isolate (as he reports in his 1987 "Retrospective Epilogue", Grice 1989: 359) a "region of signification which has special claims to centrality". Retrospectively, he identified two features • "which I shall call respectively 'formality' and 'dictiveness', with seemingly equally strong claims to provide for us a rationally reconstructed interpretation of the initially hazy feature of "centrality"; the first is saliently present in cases "in which the items or situations signified are picked out as such by their falling under the conventional meaning of the signifying expression rather than by some more informal or indirect relationship to the signifying expression"; the second, in "those instances of signification in which what is signified either is, or forms part of, or is specially and appropriately connected with what the signifying expression (or its user) says as distinct from

\footnotetext{
2 Notoriously, Cappelen and Lepore (1997) point out this fact. They go on to invoke it, in my view unconvincingly, to defend truth-conditional theories of meaning from standard (in my view, compelling) criticisms.
} 
implies, suggests, hints, or in some other less than fully direct manner conveys" (ibid.: 359-60).

I agree with Kent Bach (1994) that in order to get clear about what is semantically central we should distinguish two importantly different notions of saying and what is said. According to Bach, they can be usefully explicated by appealing to "Austin's distinction between locutionary and illocutionary acts. Austin, it may be recalled, defined the locutionary act . . . as using certain 'vocables with a certain sense and reference' [. . .] That sounds a lot like Grice's notion of saying, except that for Grice saying something entails meaning it: the verb 'say', as Grice uses it, does not mark a level distinct from that marked by such illocutionary verbs as 'state' and tell'•, but rather functions as a generic illocutionary verb that describes any constative act whose content is made explicit" (op. cit., 143). ${ }^{3}$ I offer below my own elaboration of the notion of locutionary saying, to which I will henceforth refer as semantic content or just content. But we must first concentrate on the other notion, illocutionary saying, which, like Bach, I take to be the one Grice intended, the one captured by the two features of formality and dictiveness.

What is said, in this Gricean illocutionary sense, is intuitively related to what a competent speaker could take to have been made explicit in a literal utterance of a declarative sentence. Unlike Bach, however, I do not think that this should be understood as generic speech act, of which assertion is a paradigmatic species but not the only one-swearing, conjecturing, predicting, reminding and supposing would be others. Instead, I think (but will not defend here) that it is methodologically a better option to think of what is said in the illocutionary sense as the specific act of assertion: the act made by default when literally uttering sentences in the declarative mood. For present purposes, I will also count the mental acts (the judgments that assertions express and the belief-states that they in their turn, I take it, are intended to fix or settle on) which overt assertions express as assertions made "in one's heart", as it were. It is distinctive of illocutionary acts that they fall under norms, in fact it is constitutive of them to fall under certain norms; for instance, I think that something close to Williamson's knowledge-rule is the constitutive norm of assertion. ${ }^{4}$ However, truth, in the fundamental sense in which I will be using it here, is at least a derivative norm constitutive of assertion.

The notion of illocutionary saying is thus pragmatic; but it is related to semantics, in that, as we are characterizing them by relying in part on Grice's formality criterion, assertions are made by default with expressions having certain conventional meanings, and they are determined by those conventional meanings - they are made with sentences of a natural language (English), with semantic features ascribed to them by the best semantic theory for it $\left(\mathrm{ST}_{\mathrm{E}}\right)$, and

\footnotetext{
3 Salmon (1991) and Ziff (1972) have argued for similar views.

${ }^{4}$ García-Carpintero (2004) argues for this.
} 




Relativism, Vagueness and What is Said

they have the feature they do in virtue of them. This semantic theory is, I will be assuming following Lewis, "one suited to play a certain role in a systematic restatement of our common knowledge about language... the detailed and parochial part — the part that would be different . . . if we were Japanese" (Lewis 1980: 23-4). Now, I understand the job of semantics to be (in accordance with what I think Lewis says here) to give a systematic characterization of what is said in the locutionary sense, i.e., of content.

More specifically, $\mathrm{ST}_{\mathrm{E}}$ will regiment sentences at a logical form level (LF), at which it will make explicit syntactic features that contribute to determine semantic features; at that level, sentences by means of which assertions are made will be analyzed into a force-marker and a sentence-radical. The same sentenceradical occurs with different force-makers (John will be home tomorrow; John, be home tomorrow), and, of course, the other way around. As the more detailed view about semantics outlined later will make clear, what $\mathrm{ST}_{\mathrm{E}}$ ascribes to the sentence-radical by means of which an assertion is made is a feature of content, of what is said in the locutionary sense. I will refer to those features of sentence-radicals as sr-contents, purposefully avoiding the usual 'proposition', unless this is convenient to make a point in familiar terms, because, as I will explain, I want to leave it open, as something independent from our discussion, whether or not sr-contents are more relativized than propositions are understood to be.

As I said before, the interpretative claim I will be defending here is that we must distinguish truth as applying to illocutionary sayings, from its use in applying to locutionary sayings. Moderate truth-relativism has to do with whether or not truth for sr-contents is more or less relativized in unexpected ways, while keeping truth for assertions absolute; radical truth-relativism has to do with whether or not truth as a feature of assertions should in addition be relativized. The main reason for this is that the motivation presented for relativism by its proponents comes from alleged cases of "faultless disagreement"; but in order to evaluate these cases, we have to do it in the terms that I propose, or corresponding ones. ${ }^{5}$ Relativists grant their opponents that it is prima facie difficult to make sense of (not to say that there are) those cases, after all their theory is supposed to be novel and exciting; but this can only be so, I will argue, if the truth whose relativization is posited is the truth of assertions, not just that of the contents that $\mathrm{ST}_{\mathrm{E}}$ ascribes to the sentence-radical by means of which they are made. ${ }^{6}$

5 This is my motivation for taking a stand on controversial issues, such as those regarding what is said, as I am doing in these paragraphs without, of course, being able to provide an acceptable justification for them. To critically examine the debates requires, I will argue, some distinction along the lines of the one I make concerning truth as a property of contents and truth as a norm of speech acts; thus, I might as well invoke the one I think is best.

6 The truth-relativism issue arises not just about speech acts, but also about the mental acts they give expression to. I am assuming (and this is why I intend what I want to say to apply also to judgments, understood as "utterances of sentences in one's heart") that a distinction corresponding 
$\mathrm{ST}_{\mathrm{E}}$, we have said, ascribes to sentences by means of which assertions are made based on what our common knowledge of English tells us about them. According to such common knowledge many such assertions are at most contingently true. An assertion made with an eternal sentence such as 'fluorite structure is a lattice' is true, but it might have been false had the actual world where the assertion occurs been different, in ways that (let us grant, for the sake of the example) all our common knowledge of English tells us, it might have been. ${ }^{7}$ This, given the bond between meaning and modality appreciated after Carnap's (1956) elaboration of Tractarian ideas, leads $S \mathrm{~T}_{\mathrm{E}}$ to ascribe to sentences (to sentence-radicals, on account of the facts about compositionality presently to be mentioned) functions from possible worlds to truth-values.

Given my main interpretive claims, it will be useful to distinguish henceforth, when the distinction matters, 'i-truth' from 'l-truth'. On account of contingency, and given the facts about the metaphysics of basic contents just rehearsed, $\mathrm{ST}_{\mathrm{E}}$ will ascribe to sentence-radicals sr-contents that determine (henceforth, for convenience's sake, which are) functions from possible worlds to l-truth-values. These contents, being generalizations concerning distributions of l-truth-values across possible worlds, are thus possible-world neutral. No relevant relativity ensues for truth as the fundamental constitutive property of assertions, because we assume that the truth of an assertion made by combining a force-marker with a sentence-radical results from applying the sr-content to the world where the assertion occurs. We are assuming the contingency of 'fluorite structure is a lattice'. Take a possible world in which this is false, and imagine that English is spoken there, and that an informed speaker A assertively utters 'fluorite structure is not a lattice', while his counterpart B in another world closer to actuality utters 'fluorite structure is a lattice'. Nobody would want to sustain the possibility of substantive "faultless disagreements" supporting controversial philosophical views on such a case, even though $A$ and $B$ are asserting contradictory contents (contents inconsistent with each other), and even though both A's and B's assertions are true.

What explains the nonchalant attitude vis-à-vis this form of truth-relativism that these facts manifest? I submit that the reason is that, in the relevant sense, the proper specifications of the core correctness conditions of the speech acts are not really contradictory. For those specifications to be really contradictory, in any sense potentially engendering unexpected cases of faultless disagreement, it is not enough that they concern contents that our semantics represents as complementary exhaustive functions from worlds to truth-values; it is in

to the one I will be making here, between truth for contents and truth as a norm of acts, also applies straightforwardly to mental acts. This, I take it, does not require any controversial view about the relative priority of thought and language.

7 In any case, this is what I will assume for the sake of our goals here. If one thinks that the structure of compounds such as fluorite is essential to them, one should consider instead some other example. Here we just need any atemporal, contingent truth. 
addition required that they be predicated of one and the same actual world. I propose to put this for present purposes as follows: although both A and B assert contradictory l-truth conditions, and although both assertions are $\mathrm{i}$-true, $\mathrm{A}$ and $\mathrm{B}$ are not contradicting themselves because they are not asserting the same i-truth-condition. ${ }^{8}$ An l-truth-condition is what our semantics ascribes to the sentence-radicals by means of which assertions are made; they are shared by assertions and orders, and they are what sentential operators like truthfunctions operate on. On account of the facts about contingency, and the relation between meaning and modality, they involve relative l-truth-values: they are non-constant functions from worlds to l-truth-values. However, the i-truthconditions of assertions are still absolute, because they consist of the application of these l-truth-conditions to a particular possible world where the illocutionary act occurs. ${ }^{9}$

MacFarlane notices this (2005a: 326); perhaps this was also the reason why his earlier (2003) publication on the future contingents issue studiously avoids talk of propositions, officially speaking instead of utterances. Now, however, he thinks that this was wrong, on account of facts about ordinary usage: "there is something a bit odd about calling utterances or assertions, in the 'act' sense, true or false at all. We characterize actions as correct or incorrect, but not as true or false" (2005: 322). But, as Austin (1950: 119) — who had as good an ear for common usage as anybody - pointed out, it is at the very least as much far away from common usage to predicate truth of propositions, in the philosophers' sense. ${ }^{10}$ In any case, this is neither here nor there. If there is anything clear that

8 It should be clear that-contrary to what Stanley (2005: 132, fn) claims in discussing MacFarlane's use of this very same point-appreciation of this point does not at all depend on accepting Lewis's modal realism. Stalnaker's views on the metaphysics of modality are as contrary to modal realism as it can go, but his conception of "propositional concepts", crucial to his philosophy of language, depend on evaluating assertions (including those with identical propositional contents) made at different worlds; and this is all I need for the point I make. The point itself could be made

- Q3 modally, without referring to or quantifying over possible worlds: an assertion made with • "fluorite structure is a lattice' is true, but it might have been false had the actual world where the assertion occurs been different, in ways that (let us grant, for the sake of the example) for all we are required to know to fully understand the assertion, it might have been. Of course, contingency is very common, and the assertions we are mostly interested in are made in the (one and only) actual world, which explains why we do not need in general to pay attention to the fact that the actual world is strictly speaking part of the truth-conditions for assertions. But it is worth appreciating this, because it helps us to see that the further, not-so-vacuous relativizations of contents we are about to consider are as much independent from the radical relativist claims as this widespread one is.

9 The main points made here are in agreement with Austin's (1950) views about truth; but here we only need to assume them for convenience, to make sense of the relativism debate.

10 MacFarlane is very clear about the interpretative claim I am making (in fact, reading his work and talking to him greatly helped me to appreciate it myself); now that he wants to present relativism as a view about propositions, he is forced into solecisms which sound to me at least as weird as the ones that lead him to them: he needs to appeal to a distinction between the context of use and the context of assessment of propositions, contexts being in his view concrete historical situations. If propositions are atemporal and amodal abstract entities - as in Schiffer's (1996) characterization-, this only makes sense derivatively: the context of a proposition is that of an 
these debates show, it is that philosophy is necessary; quietism is the position or attitude that is more clearly wrong. Commonsense intuitions about these matters are confused; a philosophically well-developed conceptual battery is needed to straighten them out. ${ }^{11}$ I will use assertion, now in the object sense (in contrast with the act sense) for i-truth-conditions, as an alternative to make sense of the relativism issue to philosophers' propositions and to content. In an utterance of an eternal contingent sentence like 'fluorite structure is a lattice', the content expressed has only relative (l-)truth-value. But the assertion itself has nonetheless an absolute (i-)truth-condition, which correlates well with the perception that the disagreement between the inhabitants of different worlds A and B we considered before is not in any way worth noticing: in the present sense, they are making different assertions.

The merits of my interpretative claim can be further appreciated if we introduce now into the picture some of the facts of indexicality. As examples such as (1) and (2) below show, $\mathrm{ST}_{\mathrm{E}}$ must deal with the fact that our common knowledge of English tells us that which assertions are made with many English sentences (what is said with them, in the Gricean privileged illocutionary sense) depend on facts about the contexts in which instances of the expressions are used to make them; in my view, it depends on properties of the tokens themselves, because in many cases it is their properties as physical items (their locations in time and space, their causes and effects) that are relied upon. The dialogues that follow are common tests, which reveal the ordinary perception that the assertions at stake have different contents; I use '?' to mark the perception of infelicity, whatever its source.

(1) (A): I am hungry.

(B): (?) A said/thought that I am hungry.

(2) (A, at 3 a.m.): now it is 3 a.m., October 3, 2000.

(B, at 4 a.m.): now it is not 3 a.m., October 3, 2000.

(A, reacting to B's assertion): That does not contradict what I said // (?) Then I guess I was wrong after all before.

Indexicality and contingency are related; however, as Kaplan (1989) and Lewis (1980) have shown, $\mathrm{ST}_{\mathrm{E}}$ must treat them differently: the way in which indexicality makes the truth of assertions dependent on facts about the context in which they take place differs from the way in which contingency makes it so dependent. $\mathrm{ST}_{\mathrm{E}}$ will capture this by means of something like Kaplan's (1989)

act in which the proposition is expressed or appraised. But then it is clearer to discuss directly the features of the relevant acts, as I am suggesting, soberly remembering that, as Fred Dretske once put it, it is the philosopher's fate "to talk funny" at some point or other.

11 Although, I will suggest, in many cases - and we will find instances here-different philosophical proposals, whose proponents maintain fiercely hot debates, are to all relevant purposes notational variants and could do the job equally well. Because of this, I do not claim anything more than instrumental virtues for my own suggestions. 


\section{Manuel Garyia run06.tex V1-February 6, 2008 8:49pm Page 137}

Relativism, Vagueness and What is Said

two-dimensional distinction of character and content, dependence of content on context and of content's truth-value on circumstance of evaluation; i.e., by somehow or other ascribing to sentence radicals semantic values describable by means of the two-dimensional matrices familiar from Stalnaker (1978). These two-dimensional matrices provide in my view a good elaboration for present purposes of Bach's notion of locutionary saying. On this proposal, the semantic content of a sentence radical is its full matrix; this is what we should expect for $\mathrm{ST}_{\mathrm{E}}$ systematically to deliver. ${ }^{12}$ Notice for later use that, as Stalnaker insists, they provide alternative propositions for sr-radicals to convey; in addition to the "horizontal" propositions, there are now the "diagonal" propositions, which, at least in some cases, allow for a reconstruction of Kripke's distinction between metaphysical and epistemic modalities - as in relatively uncontroversial examples such as '(actually, fluorite structure is a lattice) iff fluorite structure is a lattice'. ${ }^{13}$

Now, in spite of the indexicality of 'I' and 'now' revealed by (1) and (2), David Lewis (1979) has notoriously proposed to deal with the phenomenon of what Perry (1979) calls the "essential indexical" by in effect ascribing to sr-contents a further relativity in the circumstances of evaluation than that required by contingency. On the present characterization, Lewis's proposal is to relativize the truth of the sr-content for 'I am hungry' not just to worlds, but to individuals and times too (i.e., their sr-contents are (two-dimensional) functions from centered worlds to truth-values). ${ }^{14}$ These contents, unlike the traditional ones so far considered, are not just generalizations specifying distributions of truth-values over possible-worlds, but agents and times in addition; they are thus not just possible-world neutral, but also "world-centre" neutral: the values of those parameters are not supposed to be essential or constitutive of them. But still, according to Lewis when one asserts them, what one asserts is the application of those functions to oneself at the time of the assertion (in the world of one's assertion). The truth of assertions remains absolute.

This is as it should be: as in the contingency case, no unexpected case of "faultless disagreement" is perceived if A asserts 'I am hungry' and B asserts 'I am not hungry'. If Lewis is right, B denies the very same sr-content that A asserts, while what $\mathrm{A}$ asserts can be true, and so can what B asserts; but there is no substantive faultless disagreement involved here. In the terms I am proposing, the relativization posited by Lewis is moderate, because, in the end, it

\footnotetext{
12 This is not strictly speaking correct, but it will do for present purposes. $\mathrm{ST}_{\mathrm{E}}$ should also provide some information about the conventional meanings of moods, and also about conventional implicatures or conventionally signaled presuppositions, and this cannot be accurately represented merely by means of the two-dimensional matrices.

13 See García-Carpintero and Macià (2006).

14 Lewis only considers relativization to an individual, but this is because of his fourdimensionalism about material objects; on a three-dimensional view, his proposal would require the further relativization, which is independently needed if 'now' creates similar problems.
} 
is only l-truth relativization; $\mathrm{i}$-truth remains absolute. In a first-personal assertion such as one made with 'I am hungry', content according to Lewis's proposal only determines relative (1-)truth-value. But the assertion has nonetheless an absolute (i-)truth-condition, which correlates well with the perception that the disagreement between our illustrative inhabitants of different contexts A and $\mathrm{B}$ is not in any way of an unexpected sort, even when we focus on Lewisian de se contents. Note that I am not at all assuming that Lewis is right about these contents. What I am saying is that whether or not he is right must be decided on the basis of considerations alien to the radical truth-relativism debate. ${ }^{15}$ The arguments that can and should be provided against radical truth-relativism do not touch Lewis's proposal, only a moderate truth-relativist proposal.

The final example I would like to consider to hammer home the interpretative proposal I am making comes from debates about temporalism. Let me go back for a moment to the issue of what semantics is about, to mention an aspect not emphasized so far. $\mathrm{ST}_{\mathrm{E}}$ must account for the productivity and systematicity that our common knowledge about language manifests, by positing compositional structures. Sentence-radicals by means of which assertions are made are in addition, without any force-marker, immediate constituents of more complex expressions, and must therefore contribute to the semantic properties of the complex expressions of which they are immediate constituents with their semantic values. Relevant here are modal adverbs ('necessarily, fluorite structure is a lattice'), quantifiers ('some professor is such that he loves Mary') and temporal expressions ('Tom Cruise has been to Spain').

On the standard treatment, modals are operators; they take a sr-content as so far envisaged, and deliver another. On the standard treatment, quantifiers are not operators; syntactically what they combine with are not at LF sentence-radicals, even if they superficially seem so ('he loves Mary'), but open sentence-radicals, sentence-radicals with missing parts in them signaled by variables; they take as values functions from assignments to those variables to sr-contents, yielding srcontents. There are non-standard views of modals as quantifiers, on which what seem sentence-radicals ('fluorite structure is a lattice') are in fact open sentenceradicals that have at LF a world-variable. Regarding temporal expressions, there is no standard view in the literature. Following Prior and others in the tradition of tense logic, Kaplan (1989) takes the operator-view, ascribing to sentenceradicals ('Tom Cruise is in Spain') complex contents akin to those envisaged

15 Stalnaker (1981: 146-7) offers such considerations, on behalf of an alternative account of the "essential indexical" in terms of diagonal propositions. I am sympathetic to the account, and will be offering a structurally symmetrical one for some cases involving gradable adjectives later. But I doubt that, given the evidence that philosophers can marshal (such as the one Stalnaker appeals to), proposals such as Lewis's, Stalnaker's (and the alternative Reichenbachian reconstruction that Perry offers in the "Retrospective Epilogue" to the 1993 reprint of Perry (1980), which is in fact the one I prefer) are anything more than notational variants. 


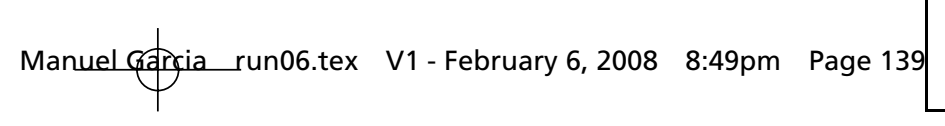

Relativism, Vagueness and What is Said

by Lewis for de se attitudes, functions from pairs of worlds and times to truth-values; King (2003), following Higginbotham (1995) and others, argues for the quantifier view.

In defense of his view about temporal expressions, King (2003: 196) appeals in part to considerations akin to those from Evans I invoke later against radical truth-relativism:

[T] hough it seems correct to hold that the things I believe, doubt, etc. can change truth value across worlds (i.e. some of the things I believe are true though they would have been false had the world been different), it is hard to make sense of the idea that the things I believe may change truth value across time and location. What would it be e.g. to believe that the sun is shining, where what I believe is something that varies in truth-value across times and locations in the actual world? It seems clear that when I believe that the sun is shining, I believe something about a particular time and location, so that what I believe precisely does not vary in truth value over times and locations.

King argues here for an asymmetry between the idea that the things we believe change value across worlds, and the idea that they change truth-value across time: the former is correct, the latter makes little sense, he suggests. In support of this asymmetry, he asks a rhetorical question and gives a small argument. I understand the rhetorical question as alluding to what still is in my mind the main reason against truth-relativism on which I will elaborate a little later; i.e., that it does not make sense to relativize i-truth, the i-truth-conditions of beliefs, because of the very same reasons that it does not make sense to relativize assertions. ${ }^{16}$ But the small argument is a non-sequitur. It is true that "when I believe that the sun is shining, I believe something about a particular time and location", but this is compatible with temporalism, and, in fact, it is exactly what temporalists like Kaplan contend. In the terminology I am using here, this is because temporalism is a view about the relativization of sr-contents, i.e., about the relativity to times (in addition to worlds) of l-truth-values. It is compatible with this to go on and give perfectly absolute i-truth-conditions for the acts and states with those contents, by having them include not just the sr-content, but also its application to the time at which the particular assertion occurs.

And it is only natural to do so, because we would not feel any faultless disagreement if $A$ asserts at $t_{1}$ 'it is raining' and $B$ asserts at $t$ 'it is not raining', independently of whether or not there is, as the temporalist claims, a common content (a temporally neutral one) affirmed in the first utterance and denied in the other. The situation is exactly parallel with respect to the relativization of contents to possible worlds. It seems equally clear that, when we believe that snow is white, we believe something about a particular possible world, even if this hardly needs mentioning; for it is conceivable to have the very same belief in

16 Remember that I am assuming that judgments are conscious episodic acts, prototypically effected by "saying in one's heart" or inwardly accepting an aural mental image of a sentence, and that beliefs are the kind of state prototypically fixed by those acts. 
a green-snow world, and there it would be false. The actual world then goes into what determines the truth-value of the belief, together with the sr-content, in an exactly parallel way to that in which, according to the standard temporalist, the time of the belief, together with its temporalist sr-content, goes into it. Hence, it is a mistake to make this kind of appeal to, in effect, the absoluteness of the truth of beliefs against proposals to, in effect, relativize their contents; for these proposals are perfectly compatible with an absolutist account of truth for beliefs (and assertions expressing them), and, in fact, that is the account that their proponents provide. ${ }^{17}$

I would like to insist that I am not claiming at all that proposals to relativize l-truth such as Lewis's about de se contents or Kaplan's for temporalism should be accepted without further ado. There are important syntactical and semantic issues, on which the question whether temporal expressions behave like standard quantifiers or rather like operators truly depends (which King (2003) also interestingly invokes in the bulk of his paper). Just after providing the characterization of the goal of a good grammar that I approvingly quoted at the outset, Lewis (1980: 24) goes on to disparage more ambitious goals, such as "that a good grammar should be suited to fit into a psycholinguistic theory that goes beyond our common knowledge and explains the inner mechanisms that make our practice possible". I strongly disagree with him about this, and, because of that, I would find highly relevant to deciding these issues, say, the kind of cross-linguistic information that contemporary linguists bring to bear on these issues. ${ }^{18}$ My claim here is merely that it is a confusion to think that they turn on what is here at stake, the philosophical standing of radical truth-relativism.

Let me sum up. There is no significant truth-relativity deriving from contingency. If the operator view of modals is correct, this is because the truth of an assertion of 'fluorite structure is a lattice' depends on its sr-content, and also on the actual world - which, with respect to i-truth-conditions plays the role of an "unarticulated constituent". If instead a quantifier view of modals were correct, then the same result ensues, in this case because at LF the sentence has a variable, which when it is asserted behaves like an indexical referring to the world in which the assertion occurs; it still goes into i-truth-conditions, but this time as an articulated constituent. There are linguistically important differences between

17 King (2003: 196) additionally supports his view in that "powerful arguments have been given against the view that the objects of belief are things that change truth-value over time", referring for such powerful arguments to Richard (1981). The argument there turns on alleged difficulties for temporalism which, as Richard himself admits in section 3 of his paper, vanish when a distinction equivalent to the one I am making between relativized sr-contents and unrelativized i-truth-conditions is applied to both beliefs and assertions. In the end, he only appears to be questioning temporalism on the basis of an alleged deficit of motivation. This is even clearer in his more recent reappraisal of the argument, Richard (2003: 38-42). I think that Prior's original motivation, close to Lewis's for de se and de nunc contents, is an adequate one.

18 Hence, I agree with (and have learned much from) King's criticism (op. cit., 226-8) of Lewis's disparaging attitude towards what he $(1980: 32-3,39)$ calls the "schmentencine strategy". 




Relativism, Vagueness and What is Said

the two views, but no debatable truth-relativism is at stake. The same applies, mutatis mutandis, to the temporal and the first-personal case.

So, what is the real issue? We have found so far no reason to relativize truth as a property of assertions, only considerations to have a more or less relativistic conception of sr-contents. The philosophically substantive issue is whether there is any reason for the radical thesis purporting to relativize truth as a property of assertions. This is, I take it, what MacFarlane (2003) argues for, on account of the possibility that the world might be genuinely ontologically indeterministic. If this is so, he contends, an evaluation of my assertion that tomorrow there will be a sea-battle contemporary with my assertion as untrue might be correct, while an evaluation tomorrow of the very same assertion as true might be equally correct. In order to make sense of this, he proposes relativizing the truth of assertions to "contexts of assessment", in this case positions in time from which truth is ascribed to one and the same assertion. Kölbel (2003) appears to be arguing for a similar view, on account of cases of faultless disagreement, in which a subject makes an assertion, another makes a contradictory one thereby rejecting the first assertion, while both conflicting appraisals of the very same assertion are correct. If truth is, as I am assuming, a fundamental constitutive norm of assertions, this does not make sense unless, as Kölbel proposes, truth for assertion is relativized to, say, personal "perspectives".

I believe these views are unacceptable, because they clash with intuitions about the nature of intentional acts that they give us no good grounds to abandon. My reasons here are, essentially, Evans' (1985: 349-50): we are not properly told what we should do, if we are told that orders should be obeyed, or promises complied with, or assertions should be true "from a given perspective", i.e., as Evans puts it, now correct, but later incorrect, "according to the state of the weather". This is, I guess, the criticism that King's rhetorical question in the quotation before hints at, "What would it be e.g. to believe that the sun is shining, where what I believe is something that varies in truth-value across times and locations in the actual world?".

We take speech acts like assertions as central cases of intentional, rational action. Rational agents should be at least by default in a position to do whatever is necessary to perform them correctly; they at least should have some measure of control about that. But it is unclear how this could be the case, if $\mathrm{i}$-truth were relativized in the way suggested by proponents of $\mathrm{i}$-truth relativism. How can I rationally take responsibility for making correct assertions, if the correctness or otherwise of my assertions depends on parameters set at different contexts of evaluation about which I lack whatever information, in ways on which I have no control? Consider a related case; imagine that A makes a promise uttering 'I myself will take B to the airport', and let us assume that there are good reasons to take the relevant content of the uttered sentence (the one contributing to the fulfillment condition of the promise) in this case to be de se, a "property" in Lewis's sense: a function from centered worlds to truth-values. 
On a moderate relativist view about de se contents, such as Lewis's own proposal, the complete fulfillment condition of the promise consists in the application of this property to $\mathrm{A}$. On an alternative radical relativist view, however, the commitment that $\mathrm{A}$ is taking here can only be fully specified at different contexts of assessment, which would determine different subjects to which the de se proposition would be applied. But, obviously, it would be irrational for A to commit himself to the fulfillment of the application of such proposition to most other subjects distinct from himself. We could have made the same point with respect to the relevant present time relative to which it is determined the later time at which A commits himself to fulfill the promise, now considering a temporalist view of the content of the uttered sentence.

MacFarlane has considered this type of objection, for the specific case of assertion, advancing a Brandom-inspired view of the norms or goals of assertion, to replace plain absolute truth. The norms to which an asserter subjects his act include things like vindicating its truth at any relevant context of assessment in response to legitimate challenges, or retracting it if shown untrue at such a context, or authorizing assertions at similar contexts. In my view, however, the point previously illustrated with the case of promises applies, mutatis mutandis, to the case of assertion. But I will not try to establish this here; it is enough for present purposes to keep clearly in sight the distinction between moderate and radical relativist views, because the fact that the latter are rather more doubtful than the former is enough to motivate adopting moderate views as opposed to radical ones, if both can equally account for whatever evidence is adduced.

Evans (1985) already made the distinction I have been insisting upon in his critical examination of the temporalist views by Prior and others. He distinguishes there several interpretations of the temporalist claims; on one of them (Evans's $\mathrm{T}_{1}$ ), what temporalists propose to relativize is the truth of assertions. (Evans says 'correctness', instead of truth, I suppose in order to distinguish it from his privileged use of 'truth', which is for contents or Fregean thoughts.) According to them, on this interpretation, "a proper appreciation of the semantic functioning of tense requires us to abandon the idea that particular historical utterances of tensed sentences are assessable, once and for all, as correct or incorrect. Rather, we must acknowledge that the evaluation of particular utterances must change as the world changes" (op. cit., 347). On another interpretation (Evans's $\left.\mathrm{T}_{3}\right)^{19}$ truth-relativism merely "registers the commonplace idea that the evaluation of an utterance depends upon the time the utterance is made (and does not vary)" (ibid., 348). This temporalist proposal corresponds to the one I have labelled before as moderate; it relativizes 1-truth to times, but not $\mathrm{i}$-truth. Accordingly, Evans's previously mentioned argument is addressed to $T_{1}$; he does not make any suggestion that such an argument in any way disposes also of $\mathrm{T}_{3}$. Against

19 We do not need to consider here Evans's $\mathrm{T}_{2}$.

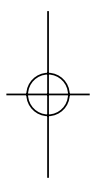




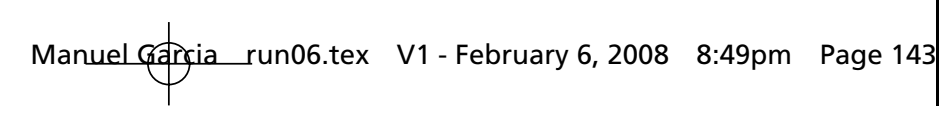

Relativism, Vagueness and What is Said

such a semantic proposal, he instead goes on to provide the sort of considerations that, I suggested before, would be really relevant; i.e., semantic arguments such as whether or not temporal operators would be on the $\mathrm{T}_{3}$-temporalist proposal akin to Kaplan's "monsters", whether or not there is something wrong with that, and so on. We will now examine a particular case for relativism, keeping these facts in mind.

\subsection{RICHARD'S TRUTH-RELATIVISM FOR GRADABLE ADJECTIVES}

Examples such as (3) and (4) below suggest the indexicality of gradable adjectives (adjectives that admit the comparative and superlative, intensifiers like 'much' and 'very' and so on), as the application of the previous tests in (5) and (6) shows:

(3) (A, assuming Bill is 1,96m tall, informally discussing the height of basketball players): Bill is short.

(4) (B, assuming the same about Bill, discussing the height of common Spaniards): Bill is not short.

(5) (B, in his context): (?) A said/thought that Bill is short.

(6) (A, in B's context, reacting to B's assertion (4)): That does not contradict what I said//(?) Then I guess I was wrong before after all.

The information about differential standards of shortness which accounts for the intuition that different contents are being affirmed and denied in (3) and (4), provided by context in those examples, can in some other cases be explicitly articulated in the uttered sentence:

(7) (A, as before): Bill is short for a basketball player.

(8) (B, as before): Bill is not short for a common Spaniard.

The evidence so far can be handled by means of a l-truth-relativist proposal, taking into account suggestions about the semantics of gradable adjectives in the literature such as Kennedy (1999) and Kennedy and McNally (2005). On a version of this view, 'short' denotes a measure function-a function from objects to degrees on a scale (in this case, of height), which in its turn is a partial ordering of degrees. This allows a natural account of the truth-conditions of the typical phrases related to gradable adjectives, such as comparative claims like 'Chicago is larger than Rome'; 'more' (or the corresponding suffix) is interpreted so that the sentence is true just in case the degree that the interpretation of the adjective ascribes to the interpretation of 'Chicago' exceeds the degree that it ascribes to the interpretation of the phrase headed by 'than'. Similarly natural truth-conditions are given for sentences such as 'John is $2 \mathrm{~m}$ tall' and 'Chicago is very large'. On this proposal, it is (paradoxically) a bit more complicated to treat 
the positive form. On one way of dealing with this, in the syntax of a sentence such as (3) there is an absolute morpheme that combines with the measure function denoted by 'short' to yield a function from individuals to truth-values. The function takes an individual $x$ to the true just in case the degree of height of that individual is at least as great as the average degree for the reference class, contextually given or, as in the examples (7)-(8), made explicit by the 'for a SN' PP.

This can be represented in the framework described before, by assuming that $\mathrm{ST}_{\mathrm{E}}$ will in effect add a further parameter to the circumstances of evaluation for sentences like 'Bill is short' - a "standard"-parameter, corresponding to a class or property, giving specific ways of being short. Relative to the standard appropriate for basketball players, 'short' will have a certain extension with respect to a world and time; relative to the standard appropriate for common Spaniards, another, and so on and so forth. In fact, Lewis (1980) suggests including such a standard in his "indexes" - corresponding to Kaplan's circumstances of evaluation. $\mathrm{He}$ calls it a "standard of precision", because he is thinking of more or less strict ways of being hexagonal, or empty; perhaps the phenomena are not strictly speaking the same, but in principle the case appears to be exactly analogous. ${ }^{20}$ In fact, we could have presented the phenomenon by contrasting (3) with (9) instead; and then (10) appears to articulate the relevant standard:

(9) (C, assuming Bill is $1,96 \mathrm{~m}$ tall, discussing the height of basketball players with basketball coaches, after concluding from careful study that players shorter than 1,9587 are not ideal for the game): Bill is not short.

(10) (C, as before): Bill is not short for a basketball player when applying such-and-such strict standards.

These examples do not thus appear to introduce any truth-relativism of the radical kind. We can treat them as just suggested, by further relativizing the l-truth-values of sr-contents to (more or less precise) standards of comparison, thus in effect counting expressions of the form for a $S N$ as operators; when gradable adjectives occur without them, as in 'Bill is short', a standard is provided by the context of the assertion, so that the i-truth-conditions remain, for all these expressions call for, absolute. ${ }^{21} \mathrm{~A}$ similar treatment can be given to Travis's

20 Kennedy and McNally (2005) argue, on the basis of interesting evidence, for a semantic difference between "relative" gradable adjectives such as 'tall' and 'rich' and "absolute" gradable adjectives such as 'empty' or 'impure'; and Kennedy (MS, sec. 3.2.1) argues correspondingly for a distinction between the vagueness of the former and the mere imprecision of the latter in some cases. I think that granting such a distinction would not affect any of the arguments in this paper.

21 Alternatively, we could count sentences like 'Bill is short' as in fact open sentence-radicals at LF; the standard provided by context would then be articulated as the referent of a hidden indexical. Jason Stanley has a well-known general argument to this effect, which depends (as it should) from independent semantic considerations. I am skeptical, for reasons close to those in Hawthorne (2004: 98-100, fn). Nevertheless, as I argued in the previous section, nothing relevant for the present

debate hinges on this.

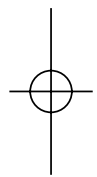


(1997) well-known example: an utterance $u$ of 'these leaves are green', with $w$ the actual world where $u$ is made, $w$ being such that the leaves demonstrated at $u$ are naturally red leaves that have been painted green. Intuitively, if $u$ is made for the benefit of a photographer, the leaves would (to use Travis's words) count as green, they would be in the extension of 'is green' w.r.t $w$; however, if $u$ is made for the benefit of a botanist seeking green leaves for a study of green-leaf chemistry, the leaves do not count as green. To deal with these cases, we can ascribe to the sentence a sr-content such that, when evaluated w.r.t. $w$ and a "count as" parameter selecting things that are green from a photographer's perspective, delivers truth; when evaluated w.r.t $w$ again, but now together with a "count as" parameter selecting things that are green from a botanist's perspective, it delivers falsehood. The standards in circumstances of evaluation will determine what counts for a three-dimensional entity with many potentialy layers and surfaces to be a certain color from a given perspective-in other words, which of the many [FN:22 potentially relevant parts count, as suggested by Szabó (2001). ${ }^{22}$ The context of the utterance will select one, when none is explicitly indicated in the sentence.

However, a closer look at cases such as (3) and (9) raises doubts; for, if we apply to them the tests for indexicality applied before, the intuitive results contrast sharply with those in (5)-(6):

(11) (C, in his context): A said/thought that Bill is short.

(12) (A, in C's context, reacting to C's assertion (11): (?) That does not contradict what I said//Then I guess I was wrong before after all.

To account for this, Richard (2004) distinguishes between two kinds of context-dependence for gradable adjectives:

- Q4 'tall' is context sensitive in so far as it requires a reference class—-something is tall for a tree/building/two year old; nothing is tall simpliciter. Other adjectives, while perhaps not requiring a reference class in order to get assigned an extension, clearly accept one. I may call a field flat and obviously be comparing it to the fields in Bucks County, or call a pond flat with the clear intent that we evaluate what I say relative to the class of naturally occurring large bodies of water. A quite different sort of context sensitivity results from the fact that (even after a reference class is determined) candidates for the extension of a term such as 'flat' or 'rich' are ordered by the degree of the relevant property (flatness, wealth), with the extension of the term being determined by "how one draws the line" within the ordering — such line drawing being something that can be done differently in different contexts (op. cit.: 237).

Other writers who argue in favor of truth-relativism, ${ }^{23}$ have also contended that there are two forms of relativism in gradable adjectives, the relativism

22 MacFarlane's suggests this account of the case in a footnote to his manuscript "Semantic Minimalism and Non-Indexical Contextualism”, commenting on Stefano Predelli's (2005) proposals. I have greatly benefited from discussion with Predelli.

23 I will later claim that they are in fact arguing for a form of moderate relativism; they explicitly commit themselves to the absoluteness (as far as their argument goes) of $\mathrm{i}$-truth. 
to a comparison standard, which lends itself to a straightforward contextualist treatment, and another one not so tractable. Thus, Egan, Hawthorne, and Weatherson (2005: 150) discuss this example:

(13) (Ant Z): He's huge (said of 5f 3, 141lb NBA player Muggsy Bogues). (Andy): Ant $Z$ thinks that Muggsy's huge.

This is what they have to say about the example: "... the report is accurate, or at least extremely natural. And ... it would have been inappropriate for the reporter to continue 'and he's right'. But crucially, ... [it is not] clear that the original speaker made a mistake... . From Ant Z's perspective, Muggsy Bogues is huge. We assume here, a little controversially, that there is $a$ use of comparative adjectives that is not relativised to a comparison class, but rather to a perspective. Ant $\mathrm{Z}$ does not say that Muggsy is huge for a human, or for a NBA player, but just relative to him. And he's right. Even Muggsy is huge relative to an ant." The example that Richard is actually discussing is in fact quite similar: "Suppose, to take an example, that Mary wins a million dollar lottery. Didi is impressed, and remarks to a friend 'Mary's rich.' Naomi, for whom a million dollars is not really all that much, remarks in a conversation disjoint from Didi's, 'Mary is not rich at all'. Suppose the salient comparison class is the same in both cases. (Both are taking New Yorkers to be the relevant fields of comparison.) Suppose that there is no difference between the two conversations in the point of assessing people as rich or otherwise" (op. cit.: 218). Graff (2000: 55-6) has rightly insisted on the importance of such sort of cases for understanding the phenomenon of vagueness; she also thinks that they involve a different kind of context-sensitivity than the relativity to a comparison class, to context-shifting significances of items relative to the interests of speakers.

It is to deal with the second type of context-sensitivity in gradable adjectives - the sensitivity to "how one draws the line", giving rise to the intuitions that (11) - (12) reveal - that Richard proposes a relativist theory. It is a radical relativist view by my lights, because it is not just a matter of appealing to the relativity to a "standard" parameter in sr-contents already countenanced before, while the truth-conditions for assertions is given not just by the sr-content, but by its application to a particular standard or class thereof given together with the assertion. Richard rejects this on the basis of the contrasting intuitions in (11) - (12). What he suggests is, instead, that the truth of the relevant assertions is relativized to "contexts of evaluation" providing different standards of precision. A's assertion (3) would be true from his own "precision-perspective", and false from C's:

What are we to say, then, about gradable adjectives such as 'rich'? Well, we could take appearances at face value... . Didi and Naomi disagree. So there is something which Didi says and Naomi denies. Within the confines of each woman's conversation, each use of 'is rich' is correct. So Didi says something true when she utters 'Mary is rich', Naomi something true when she utters the sentence's denial. This is consistent with the 


\section{-}

Relativism, Vagueness and What is Said

two disagreeing over the truth of a single claim, if the truth of the claim may be relative, so that it may be "true for Didi, but not for Naomi" (op. cit.: 225).

Although it is difficult to be totally sure, on account of the ambiguities on which I have been insisting in all those phrases - 'what Didi says', 'what Naomi denies', 'a single claim' - it appears that Richard is propounding here the radical variety of truth-relativism that Evans was objecting to with the argument mentioned at the end of the previous section, not the milder one for which he reserved his properly semantic critical considerations. The impression is reinforced when Richard gives us his views about truth, which he does in order to avoid a potentially threatening inconsistency. If we say that Didi spoke truly, given "the banality that whoever utters 'Mary is rich' says that Mary is rich" (op. cit., 233), we appear to be committed to: it is true that Mary is rich, and then to: Mary is rich. But we also want to say that Naomi spoke truly, which, on the basis of a similar "banality", together with one more application of the truth equivalence schema, ends up having us committed to: Mary is not rich. "To respond to this, the contextualist must, I think, clearheadedly embrace relativism. ... Once the contextualist accepts the banality... he must use a relativized notion of truth to formulate contextualism" (op. cit: $232-3) .24$

Richard appears to assume the following modified disquotational principle $(\mathrm{T}):{ }^{25}$

(T) If an utterance (assertion) $u$ says that $P$, then $u$ is true iff $P$

If we apply ( $T$ ) to Didi's utterance, from Didi's perspective, it follows that 'true' applies to it; if we apply ( $\mathrm{T}$ ) to the very same utterance, from Naomi's perspective, the result is that 'true' does not apply to it. In sum, as Richard suggests, 'true' has the same kind of relativity that 'green' has. Since he does not provide any other notion to evaluate assertions, it seems clear that what he is defending is genuine truth-relativism as it was characterized before.

Egan, Hawthorne, and Weatherson (2005) differ at this crucial juncture, separating moderate and radical forms of truth-relativism. They also find some use for a disquotational notion of truth satisfying (T) (op. cit.: 155), and they point out its relativistic character. However, they explicitly indicate about this relativist notion of truth that "we shouldn't restate the norms of assertion in terms of it, because that will lead to the appropriateness of assertion being oddly relativised" (op. cit.: 160). And previously they have worried, "it is not obvious how to apply some of [the norms giving conditions for correct assertion] if utterance truth is contextually relative, because one of the norms is that one should say only what is true". Then they go on to reject the suggestion

\footnotetext{
24 Note that Richard uses 'contextualism' for 'relativism', given that he takes himself to be offering the best philosophical reconstruction of contextualism about knowledge-attributions.

25 For reasons to prefer such a conditionalized version of the disquotational scheme to the more standard version, see Williamson (1994: 187-98).
} 
that "utterance appropriateness is, like utterance truth, relative to a context of evaluation", and contend instead that "the correct norm is that one should only say something that's true when evaluated in the context you are in" (op. cit.: 153).

Hence by my lights their proposal belongs in the moderate camp. Truth for assertions (what they call 'appropriateness') is absolute, and depends on applying the relativist l-truth-conditions they ascribe to utterances to the context of the assertion. We should not take too seriously the rhetoric of "faultless disagreement" about cases such as (13) which I quoted after the example (in fact, they merely say that "[it is not] clear that the original speaker made a mistake"). For, put in my terms, what Ant $\mathrm{Z}$ i-says differs from what Andy would i-say, were he to add to his report "and he's right". It is just that Egan, Hawthorne, and Weatherson's semantics allows them to recover a common 1-relativist content, akin to the temporalist common content for utterances of 'it is raining' in different contexts. There is nothing wrong with this (and the proposal I will be making to deal with intuitions such as those in (11)-(12) is structurally similar). But this is no relativism of the offending sort, unlike what Richard and MacFarlane propound.

As I have been insisting, this is no mere terminological dispute. The issue is this: there is a conception of truth-relativism - the one to which Evans was objecting - which is not the one content-relativists like Lewis about de se attitudes, or Kaplan about tenses, are making; Evans's argument does not touch this view (and he was not under the illusion that it does). Now, proposals such as Egan, Hawthorne, and Weatherson's for 'huge' (and for epistemic modals) have exactly the same shape structurally. This is obscured by their talk of relativizing "utterance truth", and by their claiming agreement with MacFarlane; in fact, as we have seen, they carefully distinguish correctness or appropriateness for assertions, and for that (exactly as the Kaplanian temporalist would do for "utterances") they give absolute conditions. Hence, they are not advancing a relativism of the kind that people find problematic for Evans's sort of reason.

Coherently with the interpretation of his view that I am assuming, Richard, like MacFarlane, does feel the threat of Evans's argument, and the need to say something in response. As I said before, MacFarlane (2003: 334-5; 2005: 334-8) resorts to a more convoluted conception of the norms of assertion - based on the one put forth by Brandom - to confront the difficulty. I have already expressed doubts about the adequacy of this move; but, as I said, for present purposes it is enough to make out the extra burden on radical relativism. I will take up Richard's response presently, but let me first outline the alternative moderate form of relativism that I would like to suggest to deal with the intuitions he relies on.

For easiness of presentation, let me refer to the intuitions of accurate crosscontextual report concerning indirect discourse reports such as (11), apparently 
distinguishing gradable adjectives (with respect to the dimension that the writers we are discussing distinguish from relativity to a comparison class) from other indexicals, as $C C R$; and let me refer to the equally distinguishing intuitions about expressions of disagreement and retractions such as (12), as $D \& R$. These intuitions conflict with the purely contextualist view I would like to defend, on which there is no relevant semantic difference between the relativity of the content-contribution of gradable adjectives to ordinary comparison standards, and their relativity to "perspectives" (Egan, Hawthorne, and Weatherson), to "how one draws the line" (Richard) or "interests" (Graff). There are two strategies that contextualists could pursue: (a) reject the very existence of intuitions CCR and DR, and (b) reject their authority, ascribing "semantic blindness" to speakers, accounting for it on the basis of specific properties of these cases. My proposal is to combine the two strategies.

As for the first strategy: I think that the intuitions in (12) (and, mutatis mutandis, those in (11)) should waver if A is allowed to explain himself better, specially if he is reflective enough and has come up with the proper tools:

(14) (A, in C's context, reacting to C's assertion (11): That does not contradict what I said; I was just saying that Bill is short for a basketball player on rough estimates for the purposes of coffee talk; we were not contemplating your levels of precision; thus I was not wrong.

Similar maneuvers are available for Richard's 'rich' example, and for Egan, Hawthorne, and Weatherson's 'huge' example. ${ }^{26}$ I have not taken polls, but apparently my intuitions here at least agree with those of other philosophers, even those otherwise sympathetic to relativism. ${ }^{27}$

Still, I think that this is only half of the story; for the other half, we need to appeal to the second strategy. I agree that the content-relativity to comparison kinds, such that of humans or that of basketball players, is much more salient to ordinary intuitions than that to "perspectives", "interests" or "ways of drawing the line". I also agree with Graff and Richard that the latter is more closely related to the phenomenon of vagueness than the former.

On the classical assumptions we have been taking for granted so far, an utterance of ' $\mathrm{A}$ is rich (for an $\mathrm{N}$ )' has a content such that the predicate divides the domain (in any possible world) into two mutually incompatible and jointly exhaustive classes. On the previously outlined semantics based on Kennedy's

\footnotetext{
26 The same applies to Graff's (2000: 55-6) 'bald' and 'blue book' examples, which she offers to justify the context-sensitivity of gradable adjectives to something other than a comparison kind. I agree with Stanley (2005: 59, fn. 8) that the examples do not ultimately contradict that, strictly speaking, there is just a form of context-sensitivity, to features or properties establishing comparison standards more or less difficult to articulate explicitly.

27 Stanley (2005: 55-6) provides a similar reply. Hawthorne (2004: 104-7), to whom Richard thanks for helping him appreciating "the importance of thinking about this sort of example" (op. cit: $247 \mathrm{fn}$. 1), appears also to concur that the intuitions CCR and D\&R can be resisted in this way. MacFarlane (2005b: $214 \mathrm{n}$.) also agrees.
}

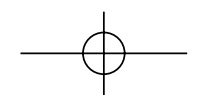


work, how this divide is effected depends on how the line in the scale of degrees of height is drawn, i.e., on what counts as greater than the average for the $\mathrm{N}$ in the context. Graff (2000) provides a contextualist-cum-epistemicist account of vagueness; on her view, what matters for the interpretation of the absolute morpheme (on the proposal sketched before) is not the average degree of the property (shortness, or shortness-for-basketball players), but what counts as significant for the conversationists' purposes in the context. Thus, with respect to a context $c$, 'short' would apply to $a$ just in case the degree that the interpretation of the adjective ascribes to $a$ exceeds the degree significant in $c .^{28}$

Now, I am prepared to concede (if this is a concession) to epistemicists like Graff that this is an accurate representation of what goes on in some very unusual contexts; imagine a use of 'tall for a flatlander' with respect to a cartoon-like situation in which most of the flatlanders in the domain are bidimensional beings without any height at all, such that having any height counts as satisfying the predicate. ${ }^{29}$ However, the condition is not met in most ordinary contexts. We simply do not care to take decisions that are required, for the predicate to properly make a semantic contribution. Fortunately, the relativist proposals we have been considering before provide alternative contents available for assertion and other speech acts. Instead of assuming the context to fix just one of the standards (the "significant" one), we may allow it (modulo higher-order vagueness, which I put aside here) to leave it open which one among those in a more or less extended class counts as significant in the context. Then we would in effect have resort to a supervaluationist semantics to give us the truth-conditions for uses of the positive form in context. ${ }^{30}$ An object $a$ is in the extension of 'short', or 'short for a basketball player', just in case the degree that the interpretation of the adjectival phrase ascribes to $a$ exceeds all the standards significant in the context. It is to contents of this kind, I submit, that the CCR and D\&R intuitions respond. On the outlined proposal, the content that is being ascribed to 'Bill is short' in (11) is, essentially, that Bill falls under the extension of 'short' in any admissible precisification - admissible, that is, given the contextual information about comparison standards; and this is the claim that A's retracts, in view of C's assertion (9).

On the alternative I suggest, thus, the intuitions in (11)-(12) are excusably confused. The content most usually i-said in, say, (3), should not be retracted just on the basis of accepting (9); and I think we lose the initial tendency to retract ourselves once allowed sufficient reflection. On the other hand, our semantic

28 See Kennedy (MS) for an interesting and detailed elaboration of Graff's view.
29 I owe these examples to Mario Gómez Torrente.

30 Fine (1975) offers the classical supervaluationist account. Alternative accounts of vagueness might well find alternative ways of accounting for the anti-contextualist intuitions I am prepared to grant, but I need to offer a sufficiently specific one and this is the one I take to be correct. See García-Carpintero (2007) for elaboration and Kölbel (forthcoming) for a similar moderate relativist account of vagueness. 


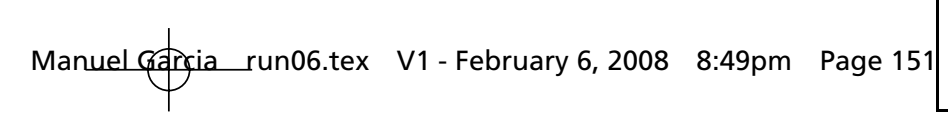

Relativism, Vagueness and What is Said

system provides an alternative content to be ascribed to (3), for (9) to contradict; but this is not the ordinary content that $\mathrm{C}$ appears to contradict.

This proposal is very close to one that Richard considers, and rejects:

"Vague expressions may be made precise, for conversational purposes, so long as those in the conversation can agree on how to do so. If conversants can't agree, the expressions retain their vagueness... neither Didi not Naomi's use of 'rich' is prohibited by the meaning of 'rich'. That is: in some contexts, 'rich' has an extension in accord with Didi's usage; in others, it has one in accord with Naomi's... The substantive dispute in [a situation in which the two turn from their respective conversations to an argument with each other over Mary's status] is something like this: whether for Didi and Naomi's purposes, the best way of sharpening the predicate 'rich' involves putting Mary in its extension" (op. cit.: 221).

In summary, on the present proposal the intuitions in (11) and (12) do not support the existence of genuine cases of faultless disagreement, and therefore do not call for any truth-relativization of the problematic kind. On the first strategy, the speakers are not contradicting each other; the content one of them denies is not the same content the other asserts. On the second strategy, the denied content is the same one affirmed, but at least one of the speakers is at fault, in the assumptions they made about the standards prevailing in the relevant context. The latter strategy involves a form of relativization, but it is one of the moderate kind, unquestioned by Evans's argument against relativizing truth as a norm of assertions.

Richard rejects proposals such as this on the basis of two considerations that I do not find convincing (op. cit:: 222). The first is that this does not allow us to characterize what is going on in cases, such as the original Didi-Naomi example, in which the two speakers are engaged in independent conversations, and we are supposed to uniformly report the contents that one asserts and the other deny while making both assertions correct. The anti-relativist accepts this, for he insists (on the basis of Evans's argument) that there is no reason to accept this as a constraint on acceptable accounts of the cases. The second is an appeal to phenomenology; in cases like those discussed, "speakers do not feel that they are sharpening a vague concept in applying it; indeed, they would challenge the claim that they are sharpening indeterminate usage". But, if this is really a feeling that speakers have, I think the anti-relativist is within his rights not to grant it any authority (on the same grounds as before).

I said before that Richard does consider Evans's argument. But what he says in response does not help, as far as I can see:

The picture of assertion behind this objection is incomplete. Suppose that I assertively utter 'Mary is rich', when it is not antecedently settled for conversational purposes whether Mary is in the term's extension. My statement, that Mary is rich, is as much an invitation to look at things in a certain way, as it is a representation of how things are. In saying that Mary is rich, I am inviting you to think of being rich in such a way that Mary counts as rich. If you accept my invitation — that is, if you don't demur, and carry on the 
conversation - that sets the standards for wealth, for the purposes of the conversation, so as to make what I say true. It is this idea - that an assertion can be as much an invitation to conceptualize things in a certain way, as a representation of how things are-that is missing from the picture of assertion on which the objection rests.

I take it that an "invitation" is a speech act akin to a stipulation, or a proposal for an agreement. If one combines the view about the vagueness in gradable adjectives suggested before with Stalnaker's view of assertion, which I find congenial, assertions such as one of 'Mary is rich' do involve such invitations. On Stalnaker's dynamic picture, an assertion, if unchallenged, changes the "context set" or "scoreboard", by being added to it. If the assertion involves the application of a vague predicate to a borderline case of application (by which here I mean a case such that the conventional meaning of the predicate does not fix whether or not the predicate applies to it), and the Stalnakerian nature of assertion is at least tacitly known by the speakers, the assertion is at the same time a proposal or "invitation" to conceive of the standards of comparison significant in the context as all of them allowing for Mary to count as rich. ${ }^{31}$

However, this by itself does not help to provide an acceptable response to Evans's concern. The question is, how does the possibility that the "invitation" is declined affect the conditions for the evaluation of the assertion as true or otherwise? If, as we have seen that Richard appears to maintain, this still requires a relativization of the problematic form, so that the assertion cannot be evaluated as true or otherwise absolutely, Evans's concern remain unaffected. As I put it before, how could it be rational for me to assert 'Mary is rich', if whether or not the act I am carrying out is correct can only be decided relative to what is the case at "contexts of evaluation" (presumably, relative to whether or not the invitation implicit in my assertion is accepted in them), over which I lack information and control?

On the proposal I have made, on the other hand, the fact that my invitation is rejected can be taken in two different ways. I can still maintain that I have made an assertion with a content involving my own take on the relevant standards of comparison, and thus I have made a correct assertion; or it rather shows that I have made an assertion with a content concerning standards that I had not contemplated, and then I have made an incorrect assertion. ${ }^{32}$ That the latter option is available might be objectionable on the basis of the purely semantic kind of considerations that Evans contemplates concerning his $T_{3}$ reconstruction of temporalism, but not on the basis of the arguments he provides against his

31 Barker (2002) discusses assertions that can only be sensibly taken as such "invitations", and provides a dynamic model for them which, although it uses a semantics for gradable adjectives slightly different from the one presupposed here, can be easily adapted to our suggestions.

32 An additional worry that I have with Richard's suggestion is that I cannot really see how he can think that his proposal survives the "phenomenological" argument he provides against the one I take to be essentially the same as the l-truth-relativistic one I have made. Seeing a potential invitation in the assertions we are considering appears to require sensitivity to the fact that the relevant concepts allow for different sharpenings. 


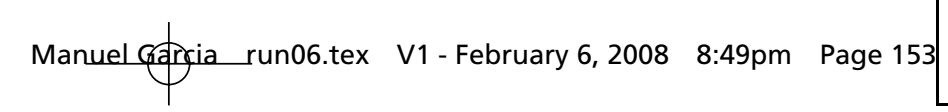

Relativism, Vagueness and What is Said

153

$\mathrm{T}_{1}$ interpretation, which, applied to the present case, appears to be Richard's. This is independent of the issue of whether or not the assertion involves also the invitation, and therefore the appeal to that, by itself, does not help.

\section{References}

Austin, John (1950): "Truth", Proceedings of the Aristotelian Society, supp. vol. xxiv; also in Philosophical Papers, J. O. Urmson and G. J. Warnock (eds.), Oxford: Oxford University Press, 117-33, to which I refer.

Bach, Kent (1994): "Conversational Implicitures", Mind and Language 9, 124-62. (2001): "You Don't Say?", Synthese 128, 15-44.

Barker, Chris (2002): "The Dynamic of Vagueness", Linguistics and Philosophy 25: 1-36. Cappelen, H. and Lepore, E. (1997): "On an Alleged Connection between Indirect Speech and the Theory of Meaning", Mind and Language 12, 278-96.

Carnap, Rudolf (1956): Meaning and Necessity. Chicago: University of Chicago Press.

Egan, A., Hawthorne, J. and Weatherson, B. (2005): "Epistemic Modals in Context", in G. Preyer and G. Peter, Contextualism in Philosophy, Oxford: Oxford University Press, $131-68$.

Evans, Gareth (1985): “Does Tense Logic Rest upon a Mistake?” In his Collected Papers, Oxford: Clarendon Press, 343-63.

Fine, Kit (1975): "Vagueness", Synthese 30, 265-300.

García-Carpintero, Manuel (2004): "Assertion and the Semantics of Force-Markers", in C. Bianchi (ed.), The Semantics/Pragmatics Distinction, CSLI Lecture Notes, Chicago: University of Chicago Press, 133-66.

(2007): "Bivalence and What Is Said", Dialectica 61, 167-90.

and Macià, Josep (2006): "Introduction", in García-Carpintero, M. and Macià, J. (eds.), Two-Dimensional Semantics, Oxford: Oxford University Press.

Graff, Delia (2000): "Shifting Sands: An Interest-Relative Theory of Vagueness," Philosophical Topics 28, 45-81.

Grice, H. P. (1989): Studies in The Ways of Words, Cambridge, Mass.: Harvard University Press.

Hawthorne, John (2004): Knowledge and Lotteries, Oxford: Oxford University Press.

Higginbotham, James (1995): "Tensed Thoughts", Mind and Language 10, 226-49.

Kaplan, David (1989): "Demonstratives", in J. Almog, J. Perry and H. Wettstein (eds.), Themes from Kaplan, Oxford: Oxford University Press, 481-563.

Kennedy, Christopher (1999): Projecting The Adjective: The Syntax and Semantics of Gradability and Comparison, NewYork: Garland.

(MS, 25/6/05): "Vagueness and Grammar: The Semantics of Relative and Absolute Gradable Predicates", at http://home.uchicago.edu/ ck0/prose.html.

and McNally, L. (2005): "Scale Structure and the Semantic Typology of Gradable Predicates", Language 81(2), 1-37.

King, Jeffrey (2003): "Tense, Modality, and Semantic Values", Philosophical Perspectives, vol. 17, Language and Philosophical Linguistics, 195-245. 
Kölbel, Max (forthcoming): "Vagueness as Semantic", in Dietz, Richard and Moruzzi, Sebastiano (eds): Cuts and Clouds: Essays in the Nature and Logic of Vagueness, Oxford: Oxford University Press.

Lewis, David (1979): “Attitudes De Dicto and De Se", Philosophical Review 88, 513-43. Also in D. Lewis, Philosophical Papers vol. 1, Oxford: Oxford University Press.

(1980): "Index, Context, and Content," in Philosophy and Grammar, S. Kanger \& S. Öhman (eds.), Dordrecht: Reidel. Also in David Lewis, Papers in Philosophical Logic, Cambridge: Cambridge University Press, 21-44, from which I quote.

MacFarlane, John (2003): "Future Contingents and Relative Truth", Philosophical Quarterly 53, 321-36.

(2005a): "Making Sense of Relative Truth", Proceedings of the Aristotelian Society $105,321-39$.

(2005b): "The Assessment Sensitivity of Knowledge Attributions", in T. S. Gendler and J. Hawthorne (eds.), Oxford Studies in Epistemology 1, Oxford: Oxford University Press, 197-233.

(2007): "Relativism and disagreement", Philosophical Studies 132, 17-31.

Perry, John (1979): "The Problem of the Essential Indexical” Nô̂s 13, 3-21. Reprinted with a "Retrospective Epilogue" in his The Problem of the Essential Indexical and other Essays, Oxford: Oxford University Press, 1993, 33-52.

Predelli, Stefano (2005): Contexts: Meaning, Truth, and the Use of Language, Oxford: Oxford University Press.

Richard, Mark (1981): "Temporalism and Eternalism," Philosophical Studies 39, 1-13. (2003): "Introduction to Part I," in A. Jokic and Q. Smith (eds.), Time, Tense, and Reference, 25-45, Cambridge, Mass.: MIT Press. (2004): "Contextualism and Relativism," Philosophical Studies 119, 215-42.

Salmon, Nathan (1991): “The Pragmatic Fallacy,” Philosophical Studies 63, 83-91.

Schiffer, Stephen (1996): "Language-Created Language-Independent Entities", Philosophical Topics 24, 149-67.

Sorensen, Roy (2000): "Direct Reference and Vague Identity," Philosophical Topics 28, 177-94.

Stalnaker, Robert (1978): "Assertion," in P. Cole (ed.), Syntax and Semantics 9, New York: Academic Press, 315-32. Reprinted in R. Stalnaker, Context and Content, Oxford: Oxford University Press, 1999, 78-95.

(1981): "Indexical Belief", Synthese 49, 129-51. Reprinted in R. Stalnaker, Context and Content, Oxford: Oxford University Press, 1999, 130-49, to which I refer.

Stanley, Jason (2005): Knowledge and Practical Interests, Oxford: Oxford University Press.

Szabó, Zoltán G. (2001): "Adjectives in Context", in I. Kenesei and R. M. Harnish (eds.), Perspectives on Semantics, Pragmatics, and Discourse, Amsterdam: John Benjamins, 119-46.

Travis, Charles (1997): "Pragmatics," in C. Wright and B. Hale, A Companion to the Philosophy of Language, Oxford: Blackwell, 87-107.

Williamson, Timothy (1994): Vagueness, London: Routledge. (2000): Knowledge and Its Limits, New York: Oxford University Press.

Ziff, Paul (1972): "What Is Said", in D. Davidson and G. Harman (eds.), Semantics of Natural Language, Dordrecht: D. Reidel Publishing Company, 709-21. 


\section{Queries in Chapter 6}

Q1. Closing quotes missing. Please check

Q2. Opening quotes missing. Please check

Q3. Please check closing quotes.

Q4. Closing quotes missing. Please Check



